\title{
Animal breeding and disease
}

\author{
Frank W. Nicholas* \\ Reprogen, Faculty of Veterinary Science, University of Sydney, Sydney, New South Wales 2006, Australia
}

Single-locus disorders in domesticated animals were among the first Mendelian traits to be documented after the rediscovery of Mendelism, and to be included in early linkage maps. The use of linkage maps and (increasingly) comparative genomics has been central to the identification of the causative gene for single-locus disorders of considerable practical importance. The 'score-card' in domestic animals is now more than 100 disorders for which the molecular lesion has been identified and hence for which a DNA test is available. Because of the limited lifespan of any such test, a costeffective and hence popular means of protecting the intellectual property inherent in a DNA test is not to publish the discovery. While understandable, this practice creates a disconcerting precedent. For multifactorial disorders that are scored on an all-or-none basis or into many classes, the effectiveness of control schemes could be greatly enhanced by selection on estimated breeding values for liability. Genetic variation for resistance to pathogens and parasites is ubiquitous. Selection for resistance can therefore be successful. Because of the technical and welfare challenges inherent in the requirement to expose animals to pathogens or parasites in order to be able to select for resistance, there is a very active search for DNA markers for resistance. The first practical fruits of this research were seen in 2002, with the launch of a national scrapie control programme in the UK.

Keywords: inherited disorder; control; DNA test; estimated breeding values for liability; selection for resistance

\section{INTRODUCTION}

In this review, the word 'disease' embraces disorders that arise independently of the intervention of any pathogen or parasite (diseases from within) and sickness resulting from pathogens or parasites (diseases from without). However, there is also a type of animal disease that straddles these two categories.

With Bill Hill having made many pioneering original contributions to animal breeding and genetics, and more broadly to quantitative and population genetics, it is perhaps not surprising that his contribution to animal breeding and disease has been less marked. In many cases, research into genetic aspects of disease is often descriptive, and, with some notable exceptions mentioned below, is relatively non-quantitative. In other words, it would have been a waste of Bill's rare mathematical talent to become too heavily engaged in describing the Mendelian inheritance or even the linkage of yet another inherited disorder. However, it is pleasing for this reviewer to note that Bill's very first paper (Hill et al. 1963) concerned an inherited disorder, and he has contributed to the general area of animal breeding and disease over the years. These contributions are covered at the end of this review.

\section{DISEASES FROM WITHIN}

Despite opinions occasionally expressed to the contrary, inherited disorders are part of nature. Mutations have been occurring ever since species existed, and

\section{* (frankn@vetsci.usyd.edu.au).}

One contribution of 16 to a Theme Issue 'Population genetics, quantitative genetics and animal improvement: papers in honour of William (Bill) Hill' germ-cell mutations have been giving rise to inherited disorders for just as long. In the years immediately following the rediscovery of Mendelism, it was natural that inherited disorders would be among the first traits to be investigated for agreement with Mendelian inheritance.

\section{(a) Single-locus disorders}

In the very first textbook of genetics, Bateson (1909) compiled a catalogue of inherited disorders in animals: hairlessness and waltzing in mice; polydactyly in guinea pigs and cats; abbreviated tails in cats and dogs; extra toe, rumplessness and 'extraordinary development of the nostril' in chickens; and webbed foot in pigeons. In the 1913 edition of Bateson's book, short-leggedness in Dexter cattle was added to the list.

This humble list was rapidly expanded as biologists in both the old and new worlds found evidence of Mendelian inheritance almost wherever they looked. However, the more they looked, the more likely they were to discover exceptions to what is now known as Mendel's second law: the law of independent segregation. True to Bateson's (1909) prediction, the chicken led the way among non-laboratory animals in this trail of discovery, because of its relative ease of breeding, and because of the wealth of variants already known to be segregating within and among breeds. Four decades after Bateson published his first list of Mendelian traits in chickens, Hutt (1949) and Warren (1949) were able to report seven disorders in a chicken linkage map comprising five autosomal linkage groups plus a group for the $\mathrm{Z}$ chromosome. Though of considerable importance in illustrating the universal consequences of crossing-over in meiosis, linkage 
mapping of inherited disorders in chickens had little practical importance.

In contrast, the need for a means of controlling a Mendelian disorder in pigs drove the initial development of the porcine linkage map. This disorder, referred to as malignant hyperthermia $(\mathrm{MH})$, exerted its powerful economic effect on pig breeding throughout the world via two related sets of clinical signs: pale, soft exudative (PSE) meat and porcine stress syndrome (PSS). By the 1980s, the locus for this disorder (now officially designated as ' $M H S 1$ ', for malignant hyperthermia, susceptibility, locus 1) had been positioned quite accurately in a linkage group comprising seven loci spread across approximately $17 \mathrm{cM}$ thought then to be on porcine chromosome 15 (Echard 1987), but later shown to be on chromosome 6 (SSC6). Because alleles at some of these loci could be detected by protein electrophoresis, it was possible to select against the so-called ' $h a l$ ' allele (thus named because $\mathrm{MH}$ could be detected to some extent in young pigs as an adverse reaction to the anaesthetic halothane) at the MHS1 locus on the basis of haplotypes for this region of SSC6. While effective, this use of linked markers was recognized as only a step along the path to discovery of the relevant coding sequence and hence the actual molecular lesion. By the late 1980s, molecular tools existed for sequencing segments of DNA, and the race to discover the molecular basis of $\mathrm{MH}$ was on. The story is worth retelling here, because it is a wonderful example of the power of comparative mapping, which is a key tool in the molecular unravelling of Mendelian disorders. Fittingly for a story about comparative mapping, the key discoveries were made by a human geneticist who initially trained as a plant geneticist.

David Maclennan and his colleagues at the University of Toronto were interested in tracking down the cause of $\mathrm{MH}$ in humans. From the pig literature, they knew that one of the loci in the porcine MHS1 linkage group was the coding sequence for glucose phosphate isomerase, GPI. Reasoning that if $\mathrm{MH}$ is linked to GPI in pigs, it would probably be linked to the orthologous locus in humans, Maclennan and his colleagues noted that GPI is located on chromosome 19 of humans (HSA19). Armed with this knowledge, they then performed a linkage analysis using markers in this region of HSA19 in families in which $\mathrm{MH}$ was segregating. Sure enough, the markers were linked to $\mathrm{MH}$ in humans. Then followed a period of academic serendipity, so often the essential ingredient of a major discovery. For many years, researchers had been studying a peptide of unknown function, called the 'ryanodine receptor' because of its ability to bind strongly to the plant alkaloid ryanodine. Later, this molecule was shown to be a calcium-release channel in skeletal muscle sarcoplasmic reticulum, controlling the flow of calcium ions in and out of muscle cells, and hence intimately involved in muscle contraction. Maclennan and colleagues realized that the gene for this molecule (called ' $R Y R 1$ ') was a candidate gene for the MH locus. Excitement mounted when they showed that RYR1 is closely linked to $\mathrm{MH}$ in humans (Maclennan et al. 1990) and in pigs (Otsu et al. 1991). The race was then on to clone and sequence the RYR1 gene in both species. With help from Alan
Archibald and colleagues from Edinburgh, who were able to provide pigs guaranteed to be homozygous for the normal and hal alleles at the MH locus, Maclennan and colleagues showed, after a Herculean effort of sequencing what turned out to be a very large gene (the cDNA comprises over 15000 bases) in both homozygous genotypes, that the two alleles differed by 18 single-nucleotide polymorphisms (SNPs), 17 of which were silent (Fujii et al. 1991). Fortunately for them, the other SNP turned out to be the causative mutation for $\mathrm{MH}$, namely a C-T substitution at position 1843 that replaces Arg with Cys in the 'lid' region of the calciumrelease channel. The presence of Cys at this position in the hal allele leaves the lid more open, thereby allowing greater flow of calcium ions, which in turn gives rise to PSS and PSE that had caused millions of dollars worth of lost production round the world.

In the present context, the important conclusion from this story is that the exceedingly important discovery of the molecular basis of malignant hyperthermia resulted directly from the creation of a linkage map in pigs. Since that time, linkage maps have been the means to discovering linked markers and then the actual molecular lesion for many inherited disorders. A recent example is complex vertebral malformation (CVM) in Holsteins (Agerholm et al. 2001), an autosomal-recessive, mostly lethal, disorder involving malformation of the vertebral column.

Another fascinating example of the power of mapping combined with comparative genomics concerns dominant white spotting. The story begins in 1986, when Besmer et al. (1986) discovered a feline retrovirus that causes cancer in cats. It turned out that the cancers arise because the retrovirus carries a host gene that becomes activated at inappropriate times following retroviral infection. The host gene was named C-KIT ('c' for cellular, and 'kit' for kitten), and the retroviral version of this same gene (classified as an oncogene, being a gene that causes cancer) was called V-KIT (' $v$ ' for viral). Having been naturally cloned by the retrovirus, the original host gene, termed a proto-oncogene, was then amenable to investigation. Linkage studies showed that KIT (its general name) maps to piebald spotting in humans and dominant white spotting in mice, suggesting that KIT is a coatcolour gene. Sure enough, that is what it is. In fact, KIT encodes the receptor for mast/stem-cell growth factor, and some elegant investigations by Andersson and colleagues (Johansson Moller et al. 1996; Marklund et al. 1998) in Uppsala, building directly on the previous work in humans and mice, have shown that this same gene is responsible for dominant white spotting in pigs, which is an economically important trait. Thus, we have the discovery of the cause of a particular type of cancer in cats leading to the discovery of a DNA marker for an economically important trait in pigs.

Yet another example of the power of mapping and comparative genomics is the discovery of the molecular basis of double-muscling in cattle. The double-muscle trait in cattle is characterized by an increase in muscle mass of approximately $20 \%$, resulting in substantially higher meat yield, a higher proportion of expensive cuts of meat, and lean and very tender meat, for which a substantial premium is paid. The trait is autosomal 
recessive, and the locus was given the symbol $M H$ (for muscular hypertrophy). The double-muscle trait occurs at such a high frequency in Piedmontese and Belgian Blue cattle that it is characteristic of these breeds. It also occurs in other breeds. Along with its obvious advantages, double-muscling also has one major drawback - a greatly increased incidence of calving difficulties, to the extent that Caesarean sections are the rule for deliveries within these breeds. However, its advantages are sufficient that doublemuscled cattle play a major role in animal agriculture in several countries, and are found in many countries. A genome scan using 213 mapped microsatellite markers in a Belgian Blue X Friesian backcross, conducted by Charlier et al. (1995), showed that the $M H$ locus is at the centromeric end of chromosome 2, approximately $3.1 \mathrm{cM}$ from microsatellite TGLA44. Two years later, McPherron et al. (1997) published the results of investigations into the gene for myostatin, $G D F-8$, a member of the transforming-growth-factor-beta-1 (TGF $\beta 1$ ) superfamily of peptides. Mice in which the myostatin gene had been 'knocked out' have a phenotype very similar to double-muscling. This immediately suggested a candidate for the $M H$ locus. Before long, both physical and linkage mapping had shown that myostatin maps to the $M H$ region of bovine chromosome 2 (Grobet et al. 1997; Smith et al. 1997), making it a probable candidate for the $M H$ gene. Then, sequencing of myostatin DNA from homozygous normals and double-muscled cattle revealed an 11-bp deletion, resulting in a frameshift and subsequent premature termination, in the bioactive carboxyterminal domain of the gene in Belgian Blue cattle (Grobet et al. 1997; Kambadur et al. 1997; McPherron \& Lee 1997). This is a region that is very highly conserved in the TGF family of peptides. The same mutation is responsible for double-muscling in the Asturiana breed (Georges et al. 1998; Grobet et al. 1998). In contrast, double-muscled Piedmontese cattle have a G-A transition that changes a cysteine residue to a tyrosine in the same highly conserved region of the gene (Kambadur et al. 1997; McPherron \& Lee 1997). In a screen of 35 double-muscled cattle from 10 European breeds, seven different sequence alleles were discovered in the coding region of the myostatin gene (Georges et al. 1998; Grobet et al. 1998). Five of these could cause a deficiency of myostatin: the $11 \mathrm{bp}$ deletion already described; an insertion/deletion in which 10 unrelated bases are inserted in the place of 7 bases that have been deleted at nucleotide 418; a C-T transition at nucleotide 610; a G-T transversion at nucleotide 676; and a G-A transition at nucleotide 938 . Two other mutants were unlikely to cause a deficiency: a C-A transversion at nucleotide 282 (resulting in a conservative Phe-Leu amino acid substitution); and a silent $\mathrm{C}-\mathrm{T}$ transition at nucleotide 414 . For most of the breeds, double-muscled animals were homozygous for one of the five harmful mutations, or were compound heterozygotes for two mutants. Obviously, there is considerable genetical heterogeneity in the cause of double muscling. Furthermore, the mutations are not all unique to one breed: two are shared by more than one breed. For example, the South Devon has the same $11 \mathrm{bp}$ deletion allele as originally discovered in the Belgian Blue (Wiener et al.
2002). However, its effect is not as severe in this breed, which raises interesting questions about regulatory factors. In addition, two breeds (Limousin and Blond d'Aquitane) have double-muscling, but do not have any of the five harmful mutations. Clearly, there are more harmful mutations to be discovered. More importantly, the discovery that mutations in the myostatin gene have a profound effect on meat yield and quality opens the way for elucidating the role of myostatin in meat production, which in turn will suggest novel (possibly non-genetic) ways of enhancing meat yield and quality.

\section{(b) Online Mendelian Inheritance in Animals catalogue}

The stories outlined above merely skim the surface of the wealth of knowledge that has been accumulated on inherited disorders in animals. What is really needed by breeders and veterinarians is a comprehensive, up-todate list of all inherited disorders. Back in the 1970s, the present author set about compiling a catalogue of all inherited disorders in non-laboratory animal species, with the aim of creating a comprehensive single resource for information on disorders and other familial traits. This resource, known as Online Mendelian Inheritance in Animals (OMIA), has been freely available on-line ${ }^{1}$ via the Australian National Genomic Information Service since 1995. A summary of the current state of knowledge is presented in table 1. It is a remarkable testimony to the power of modern genetic research tools that 126 disorders/traits have been characterized at the DNA-sequence level, and hence can be the subject of a DNA test. Moreover, this number is rapidly growing. It is also interesting to note the number of cases where mutations in the same coding sequence have been identified in more than one species, as illustrated in table 2 .

\section{(c) The challenge of intellectual property (IP) protection}

The potential availability of DNA tests arising from research into inherited disorders raises an interesting and worrisome issue. Around the world, researchers are increasingly under pressure from their employer or funding bodies to extract maximum financial gain from the development of a DNA test. In many cases, because the potential number of animals to be tested is not enormous, and the lifespan of the test will be limited to the number of years required to bring the disorder under control, it is not feasible to take out patent protection. Yet the intellectual property has to be protected in some way. A favoured and understandable strategy is to retain the discovery as a trade secret, thereby establishing a monopoly on the global market for testing. Two classic examples of this strategy concern bulldog dwarfism (Eggan \& Boichard 2000) and CVM (Agerholm et al. 2001) in Holsteins. In both cases, the research was conducted by reputable researchers working in reputable institutions, and, in both cases, not even the location of the locus, let alone the identity of the coding sequence or details of the nature of the causal mutation, were released. Instead, the world learnt of the existence of a DNA test by press release (e.g. Anon 2001) or an announcement on an Internet discussion group (Eggan \& Boichard 2000). 


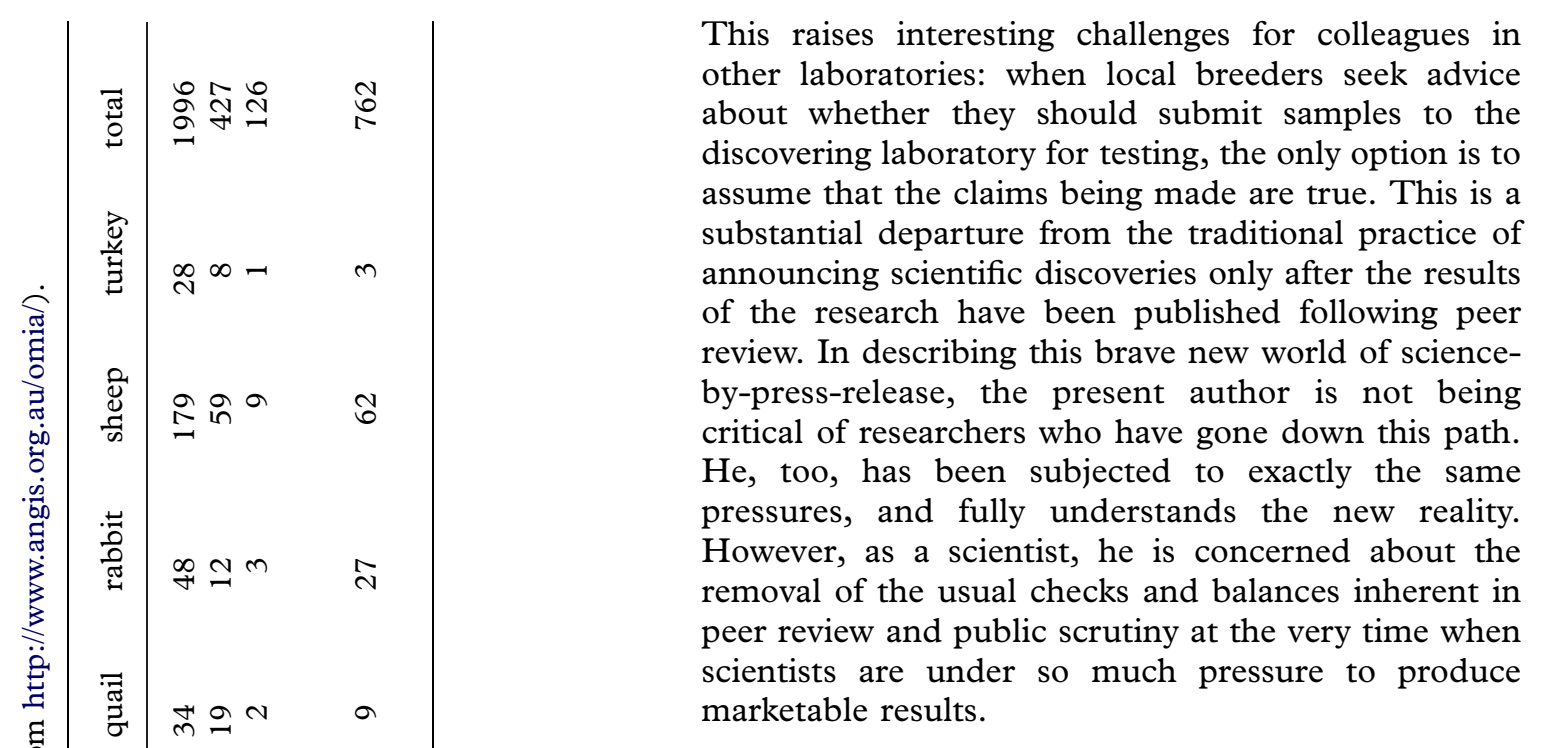

(d) Multifactorial disorders

There are many disorders that are familial because of shared genes, but which do not conform to single-locus Mendelian inheritance. Examples of these so-called multifactorial disorders are hip dysplasia and various forms of heart disease. Hip dysplasia in dogs is the archetypal example of a multifactorial disorder. Assessed by means of subjective evaluation of a radiograph of the hips, a dog's phenotype can be classified as either affected or normal (the simplest, binary classification system) or in any number of classification schemes involving more than two categories (summarized in fig. 30 of Willis 1989). Then, standard quantitative genetics tools can be used to calculate estimated breeding values (EBVs) for liability to the disorder, based on the subjective evaluation of an animal and/or its relatives. Arguably, the most powerful classification scheme is one devised by Malcolm Willis, and now used in many countries. In this scheme, nine different aspects of each side (right and left) of a radiograph are scored subjectively on a scale from 0 (best) to 9 (worst), giving a total score ranging from 0 to 108 (fig. 31 ; Willis 1989). When scored in this way, the phenotype becomes, in essence, a classic multifactorial trait, which, just as for the all-or-none classification, is readily amenable to the calculation of EBVs. While the literature has some excellent examples of the application of quantitative genetics in the control of multifactorial disorders (e.g. Maki et al. 2002), it is disappointing to note that in countries like the USA and Australia, inferior ways of using the phenotypic data are still in use, involving the setting of arbitrary thresholds above which animals are excluded from breeding. Geneticists should do everything in their power to show breeders the power of EBVs in decreasing the incidence of multifactorial disorders (Nicholas \& Thomson 2004).

\section{DISEASES FROM WITHOUT}

There have been many investigations of the extent of genetic variation in response to pathogens and parasites across a broad range of non-laboratory animals. A useful summary of evidence up to the late 1990s was presented by Axford et al. (1999). More recent 
Table 2. Disorders and traits for which the same coding sequence is mutated in more than one species (from http://www.angis. org.au/omia/).

\begin{tabular}{|c|c|c|c|c|c|c|}
\hline disorder/trait & species & & & & & \\
\hline cardiomyopathy, dilated & hamster & turkey & & & & \\
\hline coat colour, agouti & fox & horse & pig & rat & & \\
\hline coat colour, extension & cattle & fox & $\operatorname{dog}$ & horse & pig & sheep \\
\hline glycogen storage disease $\mathrm{v}$ & cattle & sheep & & & & \\
\hline goitre, familial & cattle & goat & & & & \\
\hline krabbe disease & $\operatorname{dog}$ & rhesus monkey & & & & \\
\hline leucocyte adhesion deficiency & cattle & $\operatorname{dog}$ & & & & \\
\hline malignant hyperthermia & $\operatorname{dog}$ & pig & & & & \\
\hline mannosidosis, alpha & cat & cattle & guinea-pig & & & \\
\hline mannosidosis, beta & cattle & goat & & & & \\
\hline mucopolysaccharidosis I & cat & $\operatorname{dog}$ & & & & \\
\hline mucopolysaccharidosis VII & cat & $\operatorname{dog}$ & & & & \\
\hline $\begin{array}{l}\text { muscular dystrophy, Duchenne and } \\
\text { Becker types }\end{array}$ & cat & $\operatorname{dog}$ & & & & \\
\hline $\begin{array}{l}\text { severe combined immunodeficiency } \\
\text { disease, autosomal }\end{array}$ & $\operatorname{dog}$ & horse & & & & \\
\hline sex reversal: XY female & cattle & horse & & & & \\
\hline tremor, $\mathrm{X}$-linked & $\operatorname{dog}$ & rabbit & & & & \\
\hline
\end{tabular}

knowledge has been reviewed by Bishop et al. (2002). The conclusion that can be drawn from this wealth of knowledge is very simple: additive genetic variation for disease resistance is ubiquitous. Moreover, this ubiquity exists both within and among populations. The corollary is equally simple and important-selection for increased resistance to disease will be successful.

When considering selection as a means of exploiting genetic variation in disease resistance, it is important to realize that the implications of selection can be wider than just its effect on the population undergoing selection. Much progress has been made in understanding these broader issues by a group of Edinburgh researchers, whose work is summarized by Bishop et al. (2002) and Bishop \& Stear (2003). Among other things, their broader approach embraces what they term genetic management strategies in controlling disease. One important aspect of this broader approach involves the recognition of pathways of infection.

\section{(a) Pathways of infection}

The bigger picture of infectious disease can involve various pathways of infection in relation to a host population and a reservoir of infection; there are pathways from reservoir to host, from host to host, and from host to reservoir. Not every pathogenic disease involves all pathways, but it is very useful to think in these terms when contemplating the overall impact of genetic management of disease. If, for example, selection in the host population can reduce not only infection within the host population, but also the flow of infection to the reservoir (e.g. with selection for resistance to internal parasites whose life cycle involves some time outside the host), then the reservoir will become a less important source of infection. Selection for resistance can also have an impact on populations exposed to the same reservoir that have not been selected. In other words, these pathways help us to understand the broader consequences of selection for resistance.

\section{(b) Pathogen evolution}

Common sense tells us that the greater the success of artificial selection in increasing the level of resistance in a population, the greater will be the natural selection imposed on the pathogen to evolve in such a way as to overcome the resistance. Bishop et al. (2002) argued that the greater the number of genes and mechanisms involved in resistance, the less likely is the pathogen to evolve to overcome the resistance. Another relevant argument has been put by John Gibson (personal communication); resistance that has evolved naturally during the course of the evolution of a breed will probably present greater challenges to a pathogen than resistance that has been created by artificial selection within a population during a relatively few generations. This latter argument raises the issue of introgression of resistance genes from naturally resistant breeds into commercial populations.

Another issue is the extent to which genetic variation itself is a buffer against effective evolution of pathogens. Springbett et al. (2003) presented the results of a simulation study investigating the contribution of genetic diversity to the spread of infectious disease. Their conclusions - that the lower the level of genetic diversity in the host population, the greater the chance of extreme outcomes-provide a warning against aiming simply for selection for homozygosity at all loci affecting resistance.

\section{(c) DNA markers for disease resistance}

Obviously, a major hurdle to the widespread application of selection for resistance to disease is that the requisite exposure to pathogens or parasites is often neither practicable nor acceptable on welfare grounds. Consequently, there is a very strong incentive for identification of DNA markers for disease resistance, 
which has stimulated a considerable research effort around the world.

The search for DNA markers has proceeded along two somewhat overlapping paths: conducting genome scans and testing candidate genes.

Conducting genome scans for resistance to disease requires no prior knowledge of genes that could be involved. All that is needed is a population in which there is variation in resistance, and a set of DNA markers that together cover all regions of all chromosomes. A powerful population for this purpose comprises the segregating generation $\left(\mathrm{F}_{2}\right.$ or later $)$ resulting from a cross between two populations that differ as far as possible in level of resistance, either from divergent selection or from widely disparate breeds. More common are genome scans conducted within breeds or populations on which detailed disease-resistance performance data are available. Several studies of this type have been published (see the review by Rupp \& Boichard 2003), and many more are currently underway. The result of genome scans for resistance is the identification of regions of chromosomes-so-called quantitative trait loci (QTL) - that contribute to variation in resistance.

Candidate genes are genes whose known function suggest a possible role in the trait of interest, in this case disease resistance. Examples included genes encoding immunoglobulins, cytokines, histoglobulins and pathogen receptors, and genes that have been shown to be associated with resistance in laboratory species. In the latter category are genes identified from the 1930s onwards in mice, from observations on segregating generations of crosses among resistant and susceptible inbred lines, e.g. Nramp I, now renamed as Slc11a1, encoding solute carrier family 11 , member 1 .

A major class of candidate genes comprise the major histocompatibility complex (MHC), a set of closely linked genes that encode peptides that act as the identity cards of the cell, enabling cells of the immune system to distinguish between self and non-self (the latter usually indicating infection). The atypically extensive polymorphism at these loci defies solely neutral explanations, and results in even the most ardent neutralist coming down on the side of selection (e.g. Black \& Hedrick 1997). The strong circumstantial evidence in humans that this selection probably existed when humans lived in less hygienic times led to great expectations that strong associations between particular MHC alleles and resistance/susceptibility to diseases would be found in animals, and that once found, such associations could be used for marker-assisted selection (MAS) for resistance. With the notable exception of poultry (Kaufman 2000), this expectation has not been realized, despite the many papers published with claims of useful associations. In the main, these associations have not withstood critical analysis that correctly takes account of the multiple testing that is inherent in such studies. In chickens, however, the associations between particular MHC alleles (in particular B21) and resistance to Mareks disease virus (MDV) and Rous-sarcoma virus (RSV) are strong and repeatable. Why should chickens be the exception? Kaufman (2000) has argued that it is attributable, at least in part, to the relative smallness of the chicken MHC- that it encodes far fewer loci, and thus provides less variability behind which pathogens can 'hide'. However, this is not an entirely satisfactory argument, and we await a fully satisfactory explanation of why the MHC is so strongly associated with resistance in chickens.

While candidate genes are often used in one-off tests for association with disease resistance, they also are central to further investigation of QTL. If the map of the relevant species is sufficiently populated with genes, then one can search among the genes that are colocated with the QTL, looking for positional candidate genes. The list of possible candidate genes can be increased by looking in orthologous regions of maps of the better-mapped species (such as human and mouse), for comparative positional candidate genes. The more finely mapped the QTL, the less daunting is the list of candidate genes that results from this approach. While the identification of the causative gene can shed much interesting light on the biological basis of resistance, the identification of the causative gene is not necessary for the practical application of MAS; all that is required is for a strong association between the marker and resistance (a reflection of linkage disequilibrium between the marker and the unknown causative gene) at the population level.

There is great optimism that successful application of MAS for resistance to disease will result from the considerable present activity in this area.

\section{DISEASE THAT IS BOTH FROM WITHIN AND WITHOUT}

Spongiform encephalopathies are a class of fatal neurological diseases. Clinical signs are characteristic of a progressive degeneration of the central nervous system, including pruritis, abnormalities of gait and recumbency. Death is inevitable. On post-mortem, brain histopathology shows a characteristic spongy appearance. Much remains to be discovered about the infectious agent responsible for these diseases. Present understanding can best be described in terms of the prion hypothesis, which is due in no small part to the Nobel Prize winning work of Stanley Prusiner. According to this hypothesis (DeArmond \& Prusiner 2003; Prusiner 2004), the infectious agent is a modified form of a protein encoded by a gene in the host. The name given to this infectious particle is 'prion'. The host gene is called the 'prion protein gene' (PRNP), which is a normal part of the genome of mammals and birds. Its polypeptide product, called 'cellular $\mathrm{PrP}^{\mathrm{C}}$ ', is a naturally occurring protein attached to the outer surface of neurones and some other cells. $\operatorname{PrP}^{\mathrm{C}}$ appears to play a role in maintaining the Purkinje cells of the cerebellum, which are essential for balance and muscular function. The infectious agent, called 'scrapie $\operatorname{PrP}^{\mathrm{Sc}}$, is a modified form of $\operatorname{PrP}^{\mathrm{C}}$, where the modifications involve glycosylation and the creation of intrastrand di-sulphide bonds. It is important to realize that these modifications involve no change in amino acid sequence. When $\operatorname{PrP}^{\mathrm{Sc}}$ molecules enter a previously uninfected host, they convert the naturally occurring $\operatorname{PrP}^{\mathrm{C}}$ molecules, produced by the host gene, into infectious $\operatorname{PrP}^{\mathrm{Sc}}$ particles, which ultimately cause 
clinical signs in that animal, and which can spread to other animals, both horizontally (by infection) and vertically (by maternal transmission).

In sheep, where the disease is called 'scrapie', evidence of association between particular haplotypes of the prion-protein gene and resistance to scrapie has been so strong (Hunter 1997) that national scrapie control programmes have been launched (Anon 2002; Arnold et al. 2002)-the first time that MAS for resistance to an infectious disease has been mandated at a national level. It remains to be seen whether the associations are sufficiently strong to render the schemes successful.

\section{BILL HILL'S CONTRIBUTIONS TO ANIMAL BREEDING AND DISEASE}

As mentioned earlier, Bill Hill's first paper (Hill et al. 1963) concerned an inherited disorder. In fact, it was the first report of a single-locus trait in Japanese quail. The paper is brief, but includes substantial data providing convincing evidence of autosomal recessive inheritance. In the $1980 \mathrm{~s}$, Hill contributed to two papers on the inheritance and effect of the hal allele in pigs (Carden et al. 1983, 1985). An important contribution to animal breeding and disease was the paper by Mercer \& Hill (1984), which exemplified how classic quantitative genetics could be applied to disorders recorded in a binary (all-or-none) manner. While the concept of EBV was not yet in vogue at that time, the paper dealt with estimation of heritability of liability for various disorders, and genetic correlations between liability and production traits. As mentioned above, there is still an urgent need for the widespread application of this approach, especially with companion animals. The other aspect of Bill Hill's research that relates to animal breeding and disease concerns his several investigations of the behaviour of recessive mutations in populations under partial inbreeding (Caballero et al. 1992; Wang \& Hill 1999; Wang et al. 1999), and, more generally, the conflict between artificial and natural selection (Hill \& Mbaga 1998). While these papers are written in a somewhat different context, much of their content relates to the age-old debate about the effect of inbreeding on the occurrence of autosomal-recessive disorders in animal populations. The last word has still to be written about this topic. As with so many other areas of animal breeding, exceedingly valuable insights into practical issues can be gleaned from a critical evaluation of population and quantitative genetics research that has been conducted in the broader sphere of evolution. After all, as Charles Darwin showed so elegantly, animal breeding is nothing more than applied evolution. With Bill Hill having made such a great contribution to this wider area of knowledge, the challenge is obvious; as a retirement project, Bill Hill should write a paper that brings his wealth of knowledge about the behaviour of recessives in populations to bear on the practical issues of the occurrence and control of single-locus disorders in animal-breeding programmes. Indeed, he has already dabbled with this topic (Caballero \& Hill 1992; Hill 1995; Hill et al. 1995). We eagerly await the definitive paper.
Parts of this review have drawn heavily on entries in OMIA (http://www.angis.org.au/omia) and on material in another review by Nicholas (2003). The author is grateful for the constructive comments of Steve Bishop and Alfons Koerhuis.

\section{ENDNOTE}

${ }^{1}$ http://www.angis.org.au/omia/

\section{REFERENCES}

Agerholm, J. S., Bendixen, C., Andersen, O. \& Arnbjerg, J. 2001 Complex vertebral malformation in Holstein calves. 7. Vet. Diagn. Invest. 13, 283-289.

Anon. 2001 Danish scientists reveal the gene responsible for CVM, a lethal heritable defect in Holstein cattle. Press release from Danish Cattle Club (http://www.lr.dk/kvaeg/ diverse/press-uk.htm, 17 August 2001).

Anon 2002 Member states endorse commission proposals to combat TSE in sheep and goats. EU document no. IP/02/1896, Brussels.

Arnold, M., Meek, C., Webb, C. R. \& Hoinville, L. J. 2002 Assessing the efficacy of a ram-genotyping programme to reduce susceptibility to scrapie in Great Britain. Prev. Vet. Med. 56, 227-249.

Axford, R. F. E., Bishop, S. C., Nicholas, F. W. \& Owen, J. B. (eds) 1999 Breeding for disease resistance in farm animals 2 nd edn. Wallingford: CAB International.

Bateson, W. 1909 Mendel's principles of heredity. Cambridge University Press.

Besmer, P., et al. 1986 A new acute transforming feline retrovirus and relationship of its oncogene $v$-kit with the protein kinase gene family. Nature 320, 415-421.

Bishop, S. C. \& Stear, M. J. 2003 Modeling of host genetics and resistance to infectious diseases: understanding and controlling nematode infections. Vet. Parasitol. 115, 147-166.

Bishop, S. C., Chesnais, J. \& Stear, M. J. 2002 Breeding for disease resistance: issues and opportunities. In Seventh World Congress on Genetics Applied to Livestock Production CDROM paper 13-01.

Black, F. L. \& Hedrick, P. W. 1997 Strong balancing selection at HLA loci: evidence from segregation in South Amerindian families. Proc. Natl Acad. Sci. USA 94, 12452-12456.

Caballero, A. \& Hill, W. G. 1992 Use of inbreeding in large populations. Proc. Genetics Commission, European Association of Animal Production. 43rd meeting, 1, 152-153. Rome: EAAP.

Caballero, A., Etheridge, A. M. \& Hill, W. G. 1992 The time of detection of recessive visible genes with non-random mating. Genet. Res. 62, 201-207.

Carden, A. E., Hill, W. G. \& Webb, A. J. 1983 The inheritance of halothane susceptibility in pigs. Genet. Sel. Evol. 15, 65-82.

Carden, A. E., Hill, W. G. \& Webb, A. J. 1985 The effects of halothane susceptibility on some economically important traits in pigs. 1. Litter productivity. Anim. Prod. 40, 351-358.

DeArmond, S. J. \& Prusiner, S. B. 2003 Perspectives on prion biology, prion disease pathogenesis, and pharmacologic approaches to treatment. Clin. Lab. Med. 23, 1-41.

Echard, G. 1987 The gene map of the pig. In Genetic maps (ed. S. J. O’Brien), pp. 490-493. Cold Spring Harbor: Cold Spring Harbor Laboratory.

Eggan, A. \& Boichard, D. 2000 Bulldog defect in Holstein. http://www.genome.iastate.edu/community/mail/archive/ 1824 (accessed 15 September 2004).

Fujii, J., Otsu, K., Zorzato, F., Deleon, S., Khanna, V. K., Weiler, J. E., Obrien, P. J. \& Maclennan, D. H. 1991 
Identification of a mutation in porcine ryanodine receptor associated with malignant hyperthermia. Science 253, $448-451$.

Georges, M., Grobet, L., Poncelet, D., Royo, L. J., Pirottin, D. \& Brouwers, B. 1998 Positional candidate cloning of the bovine $m h$ locus identifies an allelic series of mutations disrupting the myostatin function and causing doublemuscling in cattle. In Proc. 6th World Congress on Genetics Applied to Livestock Production 26, 195-204.

Grobet, L., et al. 1997 A deletion in the bovine myostatin gene causes the double-muscled phenotype in cattle. Nat. Genet. 17, 71-74.

Grobet, L., et al. 1998 Molecular definition of an allelic series of mutations disrupting the myostatin function and causing double-muscling in cattle. Mamm. Genome 9, 210-213.

Hill, W. G. 1995 Inbreeding: should we be concerned. Holstein Friesian 7. 77, 75.

Hill, W. G. \& Mbaga, S. H. 1998 Mutation and conflicts between artificial and natural selection for quantitative traits. Genetica 102/103, 171-181.

Hill, W. G., Lloyd, G. L. \& Abplanalp, H. 1963 Micromelia in Japanese quail. f. Hered. 54, 188-190.

Hill, W. G., Brotherstone, S. \& Coffey, M. P. 1995 A guide to inbreeding. Proc. Br. Cattle Breed. Club 50, 16-25.

Hunter, N. 1997 PrP genetics in sheep and the applications for scrapie and BSE. Trends Microbiol. 5, 331-334.

Hutt, F. B. 1949 Genetics of the fowl. New York: McGraw Hill. Johansson Moller, M., Chaudhary, R., Hellmen, E., Hoyheim, B., Chowdhary, B. \& Andersson, L. 1996 Pigs with the dominant white coat color phenotype carry a duplication of the KIT gene encoding the mast/stem cell growth factor receptor. Mamm. Genome 7, 822-830.

Kambadur, R., Sharma, M., Smith, T. P. L. \& Bass, J. J. 1997 Mutations in myostatin (GDF8) in double-muscled Belgian Blue and Piedmontese cattle. Genome Res. 7, 910-916.

Kaufman, J. 2000 The simple chicken major histocompatibility complex: life and death in the face of pathogens and vaccines. Phil. Trans. R. Soc. B 355, 1077-1084. (doi:10. 1098/rstb.2000.0645.)

MacLennan, D. H., Duff, C., Zorzato, F., Fujii, J., Phillips, M., Korneluk, R. G., Frodis, W., Britt, A. \& Worton, R. G. 1990 Ryanodine receptor gene is a candidate for predisposition to malignant hyperthermia. Nature 343, 559-561.

McPherron, A. C. \& Lee, S. J. 1997 Double muscling in cattle due to mutations in the myostatin gene. Proc. Natl Acad. Sci. USA 94, 12 457-12 461.

McPherron, A. C., Lawler, A. M. \& Lee, S.-J. 1997 Regulation of skeletal muscle mass in mice by a new TGF-beta superfamily member. Nature 387, 83-90.
Maki, K., Groen, A. F., Liinamo, A. E. \& Ojala, M. 2002 Genetic variances, trends and mode of inheritance for hip and elbow dysplasia in Finnish dog populations. Anim. Sci. 75, 197-207.

Marklund, S., Kijas, J., Rodriguez-Martinez, H., Ronnstrand, L., Funa, K., Moller, M., Lange, D., Edfors-Lilja, I. \& Andersson, L. 1998 Molecular basis for the dominant white phenotype in the domestic pig. Genome Res. 8, 826-833.

Mercer, J. T. \& Hill, W. G. 1984 Estimation of genetic parameters for skeletal defects in broiler chickens. Heredity 53, 193-203.

Nicholas, F. W. 2003 Breeding for disease resistance: general principles and latest results. Proc. Aust. Poult. Sci. Symp. $15,42-49$.

Nicholas, F. W. \& Thomson, P. C. 2004 Inherited disorders: sustained attack from several quarters. Vet. F. 168, 114-115.

Otsu, K., Khanna, V. K., Archibald, A. L. \& Maclennan, D. H. 1991 Cosegregation of porcine malignant hyperthermia and a probable causal mutation in the skeletal muscle ryanodine receptor gene in backcross families. Genomics 11, 744-750.

Prusiner, S. B. 2004 Detecting mad cow disease. Sci. Am. 291(1), 86-93.

Rupp, R. \& Boichard, D. 2003 Genetics of resistance to mastitis in dairy cattle. Vet. Res. 34, 671-688.

Smith, T. P. L., Lopezcorrales, N. L., Kappes, S. M. \& Sonstegard, T. S. 1997 Myostatin maps to the interval containing the bovine $m h$ locus. Mamm. Genome 8, 742-744.

Springbett, A. J., MacKenzie, K., Woolliams, J. A. \& Bishop, S. C. 2003 The contribution of genetic diversity to the spread of infectious diseases in livestock populations. Genetics 165, 1465-1474.

Wang, J. \& Hill, W. G. 1999 Effect of selection against deleterious mutations on the decline in heterozygosity at neutral loci in closely inbreeding populations. Genetics 153, 1475-1489.

Wang, J., Hill, W. G., Charlesworth, D. \& Charlesworth, B. 1999 Dynamics of inbreeding depression due to deleterious mutations in small populations: mutation parameters and inbreeding rate. Genet. Res. 74, 165-178.

Warren, D. C. 1949 Linkage relations of autosomal factors in the fowl. Genetics 34, 333-350.

Wiener, P., Smith, J. A., Lewis, A. M., Woolliams, J. A. \& Williams, J. L. 2002 Muscle-related traits in cattle: the role of the myostatin gene in the South Devon breed. Genet. Sel. Evol. 34, 221-232.

Willis, M. B. 1989 Genetics of the dog. London: H.F. \& G. Witherby Ltd. 